\title{
A NEW OFFERING FAHP AND FTPSIS APPROACH, PRODUCTVITY INDEXES IRANIAN CENTRAL IRON ORE COMPANY
}

\author{
Rasoul Motakiaee $*^{1}$
}

\begin{abstract}
In decision making science, an important aspect is to select one strategy from available ones and to prioritize. multi criteria decision making methods, especially fuzzy MCDM have made their way in to this field for several years. among them, analytical hierarchy process(AHP)method and technique for order preference by similarity to ideal solution (TOPSIS)have been employed more than other technique and methods have. Function productivity is among many different factors. In the climate of decision making to increase productivity. Therefore, raised question is that on which factore and how much we should put emphasis.This study tries to answer this question using MCDM models. For this reason, after primary data was collected with identification questionnaire and effective factors were categorized by using statistical analysis done with SPSS software, a primary refinement was carried out on factors and criteria. Next these factors are ranked by analytical hierarchy process(AHP), fuzzy technique for order preference by similarity to ideal solution(FUZZY TOPSIS), and Fuzzy AHP methods. Which are among the most important multi criteria techniques. Given that the results from above methods. in some cases, are not in agreement with each other, combined POSET technique was used reach consensus on ranking criteria. Finally disagreement between the results was examined by using freedman's statistical test and spearman' s correlation coefficient. With regard to the results of this study, a combined ranking method, taking ranking means, was employed to make decisions on prioritizing productivity objectives of Iranian Central Iron Ore company. Since it was impossible to choose optimal ranking method from fuzzy and non fuzzy methods. Eventually, important criteria in making policy on human force productivity were identified from management factors. Human force and customers, with management factors being the most important ones separated by management information system index.
\end{abstract}

\section{Keywords}

Productivity, Fuzzy Logic, MCDM, TOPSIS, AHP

\footnotetext{
1 - Department of Industrial Engineering and Management, Islamic Azad University of Kermanshah, Iran

*- Corresponding author. E.mail: rasoulmotakiaee@gmail.com
} 


\section{Introduction}

Nowadays, preferences should be prioritized first in order to solve complex problems while considering various social-economic issues. In other words, we should reach agreement on priority of one objective over another. Many individuals believe that life is so complex that we have to turn to sophisticated thinking methods to solve it's problems. In direction of scientific simplification reasonable and well-grounded frameworks enable us to think of complex problems in a simple way[ 1]. MCDM techniques create such a framework.

\section{Problem Definition}

In recent years, discussion around productivity has made it's way into scientific and social fields. Recently, with an increase in the number of economic firms, some severe competition has been created in the field of froduct-services productivity on the world stage. Given resoutces limitation and expensiveness, the most basic concern of present century management is competition[6]. In practice, such competition has affected organizations survival. In the midst, productivity improvement plays an important role in contributing organizations competiveness. Productivity is a measure on which we can constantly improve current conditions.

Managers often face different resources limitations. Usually, such resources include capital, raw materials, machinery capacity, human force, place, time, etc. At the same time managers see numerous goals on their way which contradict each other, that is, to achieve one goal prevents another from being achieved [6].

Therefore, managers always seek ways in which they can reach an acceptable level of goals achievement while regarding present limitations[7]. Productivity is function of many different factors which, depending on nature, mission, operational system, etc. Not only vary from on organization to another, but also have different degree of effects on productivity. So while decision making on productivity improvement, raised question is: on which factors and how much we should put emphasis [5].

In many case, decision making results are favorable and satisfactory to decision makers if decisions are studied and analyzed on the basis of some principles. By principle, we mean standards and rules employed to judge and to express rate of effectiveness in decisions making, which are outlined in 2 ways: In the from of index, and of objective[2].

Topics of improving and determining productivity indexes is a new topic within organizations, which is considered as goals and tools to improve organization. Essential aspect of reseach is to solve such problems by using reseach decisions applied operationally to fuzzy (uncertainty) environments.

Furthermore, due to the vastness of operational input and output, west region power corporation needs to elevate the level of human force productivity as well as the level of effectiveness in managerial decision making.

Given that the subject of productivity and factors affecting it have not been studied yet in relation with west region power corporation, the aim of the research is to use multi criteria decision making models in order to give an answer to this question: on which factors and how much we should put emphasis in order to increase productivity within this organization.

\section{Reseach Literature}

\subsection{Domestic Studies}

Kazemi,Abtahi(2002); Carried out a study titled determining factors affecting productivity and some plans to improve it to be used by managers of Mibod-Iran tile corporation. They employed classic AHP method. With some modification, data was extracted from tomas L.saaty's spectrum; Then criteria were ranked the most 
important of which are appropriate salary\&wage, and appropriate management information system(MIS) indexes.

Mirnezhad(2004); Speaks of measuring product volume and used material like needed land and capital in order to measure producticity performance within pars refractory brick factories. He employed LINMAP, TOPSIS, and AHP methods and fuzzy trapezoid numbers as required data. In his study, he ranked each option individually by using each of these techniques and, finally, identified long and short-term planning, management style, and energy consumption reduction as the most outstanding standards on productivity performance.

Aminifaskhoudi(2007); studied evaluation of decision units using group AHP decision making model. Data he used was from L.saaty's spectrum in fuzzy form. using dynamic planning model, he introduced such criteria as creativity. Fluency and innovation among important components of decision making.

Mohamadzadeh,etat(2008); Investigated project selection by fuzzy TOPSIS\&AHP techniques, and tested the usage of extend analysis method and ideal positive and negative method. Using these methods, he identifies and ranks important projects. finally, those projects are chosen that have a high rate of internal efficiency.

Ghazanfari\&Ibn-Alrasoul(2008); Studied comparison of performance measurment systems and selection of the best of them using fuzzy TOPSIS method. In this research, different systems of measuring performance were examined and their comparison indexes were also defined. then, knowledgeable experts determined the score of each system at different indexes for conditions existing in iranian organizations. Since these scores are expressed by experts, they have some uncertainty, therefore, fuzzy linguistic variables were used. Results from this reseach show that selected systems must be self-assessing and self-controlling.

Mohaghar\&Mostafavi(2007); Studied the presentation of a model for selecting project team by using fuzzy approach. In this research, it was attempted to provide a model for selecting a team performing a project systematically and based on scientific bases and\&or to provide some stages of that model. In this research Initially, Required Activities And Skills, Duration Of Activities, Cost Per Person, and the plan for assigning people to the project are determined in accordance with project planning. In next step, the degrees of membership of project targeted skills are specified and defined as a fuzzy set of target skills. Next, potential groups are formed by using the concept of fuzzy conjunction.

\subsection{Foreign Studied}

Mikhailov\&et at(2001); Obtained services evaluation by using fuzzy AHP technique as well as data in terms of in terms of integrated AHP weights. These researchers, eventually, ranked criteria by using fuzzy planning. On the basis of their results, pricing based on primary quality and demand was selected. According to their results, divergence rate was 0.05 .

Bai Chung \& Shou Yung(2004); Did a research on evaluating quality performance by using analytical fuzzy sequential process method, experts views and determined consistency rate of results, then ranked ideal option. Among the most important units are indicatives in development of quality performance and of effectiveness of quality guarantee unit.

Doug Dairen Etal(2008); Did a research on optimally selecting ammunition (weapon) by using AHP and TOPSIS methods within fuzzy environment. In this research, the most significant weapon in terms of price, speed, system's resiliency, precision of hitting the target, weight, repairability of arming system, gunstock, etc. Is evaluated and selected. AHP is used to select fuzzy TOPSIS model and to weigh criteria. At first, decision team and decision hierarchy tree containing criteria and options are formed. The result of the research was that the experts views are combined by using statisticasl geometric mean technique and ideal options are selected by using fuzzy TOPSIS ranking technique. Finally, given that the types and names of weapons couldn't be expressed due to security reasons, the best weapon selected was denoted by abbreviation $\mathrm{C} 2$. 
Chi ta ai, Yawling(2000); Selected a model for enterprise resource planning(ERP) by using fuzzy AHP. The weight obtained by AHP model was considered as decision matrix, criteria of production and management were compared fuzzily; and a system was chosen which had transport potential.

\subsection{An analytical review of studied performed}

Extensive library and field studies have been performed to evaluate criteria and extract indexes for present research. It should be noted that most models selected in previous research, which was highly limited, and used to solve decision problems were nearly the same and performed the tasks and ranking process mostly by using classic AHP model and traditional TOPSIS method, and they were based on one or two models.

Perhaps it can be said that one aspect to choose present research was it's innovative aspect. It uses a wide variety of non fuzzy certain and fuzzy certain models. And given the issues of improving productivity and determining it's indexes are novel issues within organizations. It is considered as a tool and objective of organizational improvement, on which a little research has been done. This research novelty and innovative aspect is that it solves such problems by research applied decisions in operations done within fuzzy (uncertain) environments. This research was done in order to answer some questions raised: which model is more suitable for each decision; to what extent decisions made by these models are different; and to what extent the result of applying these techniques collectively is different. Another innovation of present research. Therefore, is analyzing sensitivity between decision making models. One reason for using the method of rankings combination in present research is to solve the problem of dissimilarity of models results by reaching consensus on them.

Perhaps another reason for this research innovation is to use 5 testable hypotheses in quantitative problems for the first time. Usually, hypotheses are not used in quantitative models of research in operations and doing academic research with such models. Also, it should be noted that most models selected in previous research, which was highly limited, and used to solve decision problems were nearly the same and performed the tasks and ranking process mostly by using classic AHP model and/or traditional TOPSIS method, and they were based on one or two models. And given that the issues of improving productivity and determining it's indexes are new issues within organizations, it is considered as a tool and objective of organizational improvement, on which a little research has been done and also it uses various certain and uncertain models.

\section{Theoritical description of selected model}

\subsection{Productivity}

Term productivity was used first by Franswa Kenne, mathematical\&economist advocating physiocracy of nature rule; and at that time, efficiency was defined as real time of doing work to standard predetermined time ratio[6]. International labr organization (ILO) defines productivity as input to one of production factors( land, capital, work force, management) ratio. Productivity is defined systemically as follows:

((outputs to inputs of a system ratio)) $\mathrm{P}=\frac{\text { output }}{\text { input }}$

Work scarcity has the closest meaning to word unlimited or free. Resources are various kinds of labor, capital, land and management. Given that limited resources and facilities are available to organizations, and that a large number of resources are not renewable or their reformation process takes myriad of years or some resources are so scarce that providing them requires huge money, and that population growth rises resources limitation increasingly. Therefore, the only logic way to solve these problems is to gain maximum efficiency and profit from minimum resources. This point is hidden in productivity issue that can be in favor of organization itself as well as of society it serves[7].

Essentially, to reach the highest rate of productivity, it is necessary to identify and prioritize these factors according to scientific standards and principles and in terms of their importance to organization; Then, required plans and executive programs are formulated to improve productivity[6]. 


\subsection{Fuzzy Logic}

In 1965, fuzzy set theory was developed by Lotfizadeh, originally Iranian scientist at California University, for unknown and uncertain problems and, since, it has found applications in modeling for complex systems and provides a natural technical tool to evaluate phenomenon [11].

\subsubsection{Triangular Fuzzy Numbers}

Doing calculations with fuzzy numbers is highly time-consuming and complex because of their particular structure. Certain fuzzy numbers are employed in calculations to facilitate fuzzy numbers application[9].

In present research, triangular fuzzy numbers were used for their usability and calculation simplicity.A triangular fuzzy number can be displayed with an orderly triad $(l, m, u)$.

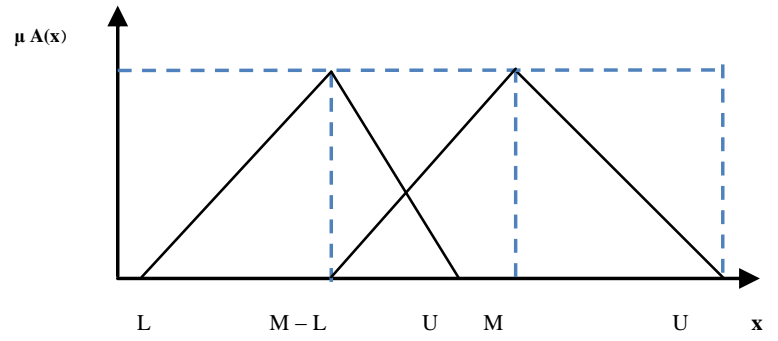

\subsubsection{Defuzzying}

Defuzzying is a technique used to transform fuzzy numbers into certain real numbers. The technique used in present research is called interval methods, as shown in following equation[13]: $\quad \mathbf{d}(\mathbf{u}, \mathbf{0})=\frac{2 \boldsymbol{m}+\boldsymbol{u}+\boldsymbol{l}}{\mathbf{4}}$

\subsubsection{Linguistic Variables}

For fuzzy set, experts should offer their opinions on each option[4]. An expert must state to what extent an option can satisfy different criteria. Linguistic variations used in this research are in the form of following numbers: Graph (1)

$\mu_{(\mathrm{x})}$

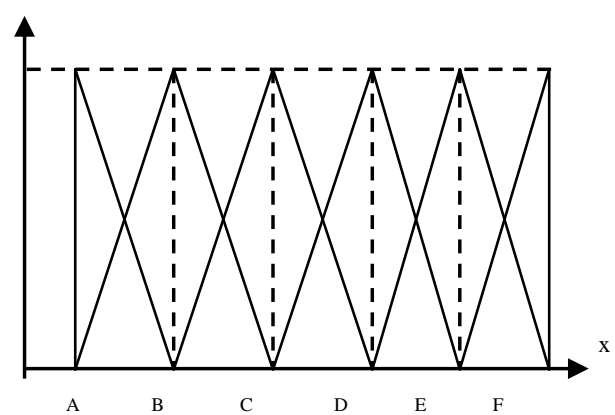

2. Function of fuzzy linguistic variables membership

\begin{tabular}{|l|l|l|}
\hline \multicolumn{1}{|c|}{$\begin{array}{c}\text { Linguistic } \\
\text { Variables }\end{array}$} & \multicolumn{1}{c|}{$\begin{array}{c}\text { Triangular } \\
\text { Fuzzy }\end{array}$} & \multicolumn{1}{c|}{$\begin{array}{c}\text { Reversed Triangular } \\
\text { Fuzzy Numbers }\end{array}$} \\
\hline Highly Poor & $\mathrm{A}=(1,1,2)$ & $\mathrm{A}=(1 / 2,1,1)$ \\
\hline Poor & $\mathrm{B}=(1,2,3)$ & $\mathrm{B}=(1 / 3,1 / 2,1)$ \\
\hline Moderate & $\mathrm{C}=(2,3,4)$ & $\mathrm{C}=(1 / 4,1 / 3,1 / 2)$ \\
\hline Good & $\mathrm{D}=(3,4,5)$ & $\mathrm{D}=(1 / 5,1 / 4,1 / 3)$ \\
\hline Highly Good & $\mathrm{E}=(4,5,6)$ & $\mathrm{E}=(1 / 6,1 / 5,1 / 4)$ \\
\hline Excellent & $\mathrm{F}=(5,6,7)$ & $\mathrm{F}=(1 / 7,1 / 6,1 / 5)$ \\
\hline
\end{tabular}

\subsection{Analytical Hierarchy Process- Group (AHP)}

As one of decision making perspectives with multiple MCDM factors, AHP technique is used to assess group or individual judgements. AHP is one of the most famous decision making techniques with several indexes[12].

Which was developed by L.saaty's in 1980. The aim of AHP is to create or form complexity hierarchy of a problem through grades classified from large to small or from general to specific matters and economic ones in 
order to gain more precision via understanding the subject[7].To perform AHP, we must construct, in the first step, the problem hierarchical tree having objective, standards, and sub standards.

In the next step, we must make tables of paired comparisons of standards and sub standards and distribute them to people participated in research. In the third step tables completed by people should be examined in terms of consistency rate, and tables with inconsistency rate more than 0.1 must be returned to individuals in order for them to re-think of their own inconsistent judgements. Eventually, individuals opinions are combined and we reach a final ranking of standards. This stage was carried out with Team Expert Choice software.

\subsection{TOPSIS Method}

This method was provided by Hwang\&Yoon in 1981[10]. In this method, M options are assessed by $\mathrm{N}$ indexes and each problem can be considered as a Geometric system containing $\mathrm{M}$ points within an $\mathrm{N}$ Dimension space[8]. It is assumed that desirability of each index increases / decreases uniformly.

Ranking method of TOPSIS is as follows: Selected option must be at the least distance to ideal $A^{+}$solution and the most distance to ideal $A^{-}$solution. Data needed by this method includes[1]:

1) Weights Vector $(\mathrm{W})$

2) Decision Making Matrix

\subsection{POSET Strategy}

Given different techniques mentioned above, it is possible to obtain different rankings for one problem. In this case, combined methods such as, Rankings Mean Borda, Kapland methods are employed to reach consensus on various rankings. Having obtained standards rankings by combined ( Rankings Mean ), we should integrate the results of these methods to gain a single for standards. This technique is called combining method.

\subsection{Research Implementation steps}

This study is implemented based on 3 steps:

1) In the first step, after the concepts were understood completely and dimensions and components of research problem were identified, open and guidable interviews were conducted with masters, managers, and experts at differents levels of Iranian Central Iron Ore company; then standards and indexes important to improve productivity were specified considering subject literature and company state's evaluation. The result of this step was indentification of 49 standards in 5 major subsets(management factors, environments, hauman force, financial factors) and 4 minor subsets (cultural, social, economic, and psychophysic factors). These factors are displayed in the form of hierarchical tree of productivity primary standards in, graph2: 


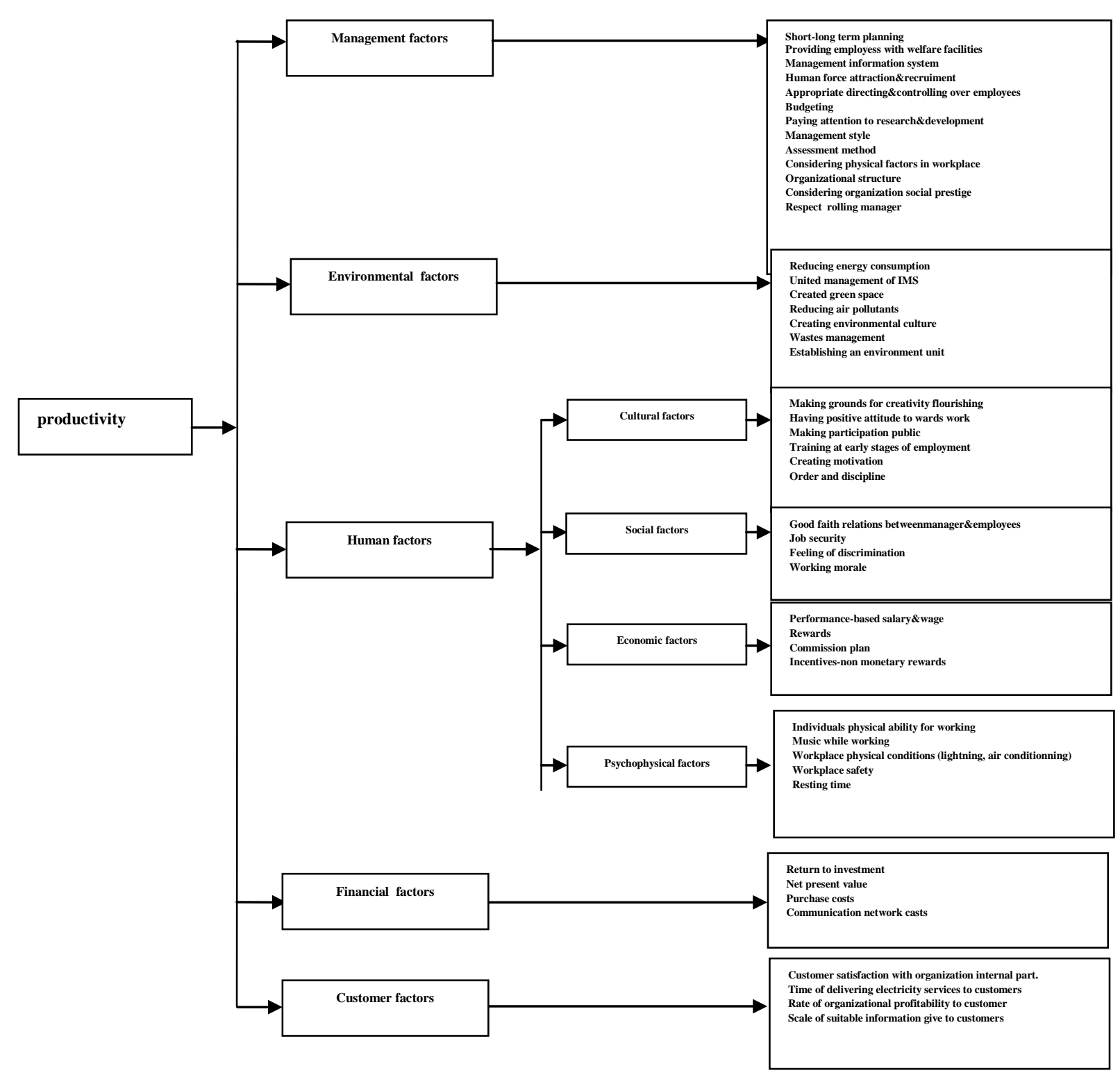

Graph2. Productivity primary standards

2) After research team (Experts)identified the most important primary standards (49 items), individuals participated in research were asked to score them according to Cahrt1:

\begin{tabular}{|c|c|c|c|}
\hline Score & \multicolumn{2}{|c|}{ Score between (1-10) } \\
\hline $\begin{array}{c}\text { Impact degree } \\
\text { (importance) }\end{array}$ & The lowest & The most probable & $\begin{array}{c}\text { The } \\
\text { Highest }\end{array}$ \\
\hline
\end{tabular}

Chart1: scoring spectrum

Due to the limitation the company imposed on us, including lower educational degrees of some employees than graduate level and management obligation to not to choose subjects randomly, we were forced to distribute only 25 questionnaires all of which were returned.

In order to integrate opinions and prioritize final standards, SPSS software was used to calculate geometric means of standards importance; then, final standards were specified.Those standards were retained that the 
lighest importance considering the results of questionnaire a analysis, that is, the group of standards with scores higher than total geometric mean of response to questionnaire (for individual members); and some standards with lower geometric mean than total mean were excluded from the process.

3) Fifteen standards were specified after completing this process which were compared by using paired comparison tables for 15-fold standards. Data from these tables was used as the basis of work of different techniques studied in order to prioritize superior standards and to select optimal model.15-fold standards extracted to be grap3. As seen from the graph, environmental and financial factors were discarded through discarding data with score lower geometric mean in accordance with process modification.

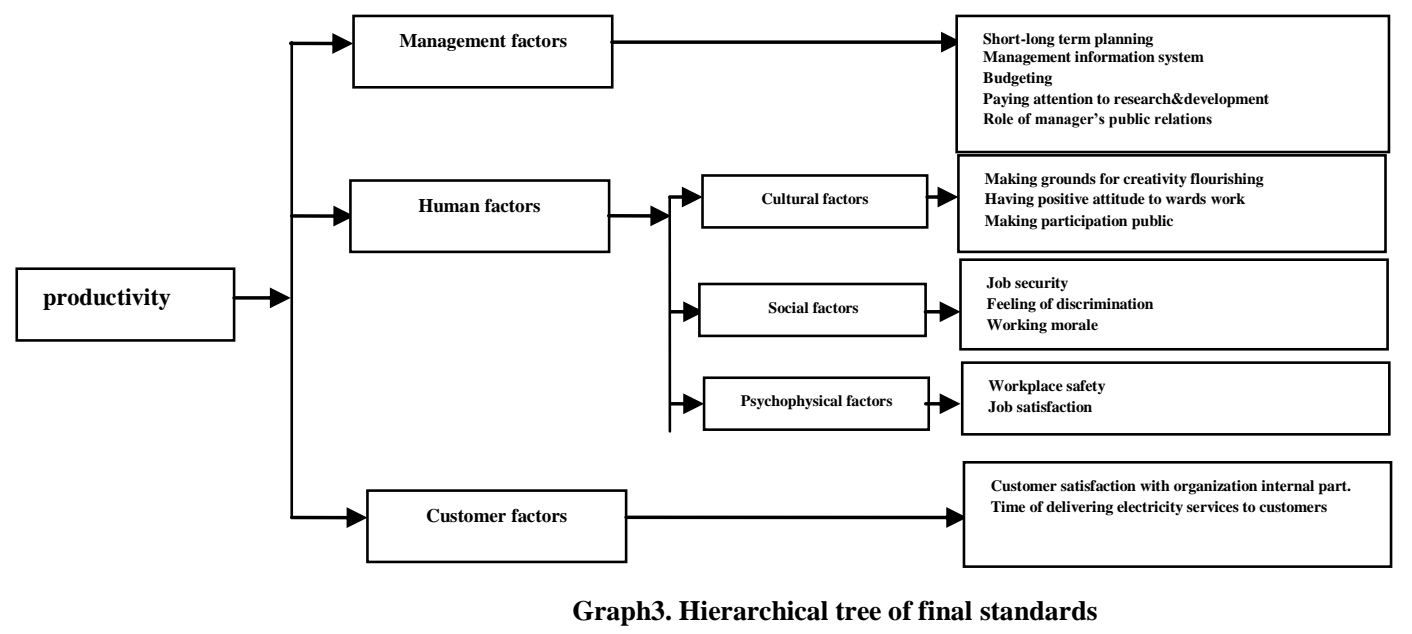

For human (work)force and organizational efficiency level, economic and financial factors are not as important as mental, motivational factors.

It is worthy to not that this research population consists of experts, managers, and supervisors working with west region power corporation. Characteristics of this population are that the subjects were from qualified experts, and that they were not selected randomly; for this reason, organization managing director selected non-randomly those experts $(\mathrm{N}=25)$ to participate in decision making team. Considering research method and that 15 of 49 primary standards were selected finally, the second questionnaire was made by using comparison tables, distributed to 25 persons (Experts), all of which were returned, in order to make estimations.

\section{Model Estimation}

\subsection{Performing Hierarchical AHP Analysis Technique}

After questionnaires were completed, expert's views were integrated by using TeAM Expert Choise software. This software has extensive capabilities to get paired persons comparision matrixes, to integrate defferent persons matrixes, and to transform them into a single matrix through geometric mean of individual elements of persons matrixes.

The procedure is as follows: after the second questionnaire, made by a FUZZY spectrum, was completed by respondents, it's paired comparison matrixes were entered into the software individually.

To determine convergence or divergence of opinions $(\mathrm{CR} \leq 0.1)$, it was necessary to calculate the divergence rate of each persons opinion matrix. Finally, 25 distributed questionnaires were collected. After the last questionnaire was entered into software and tested for divergence, the software created an integrated matrix, which contained all individuals scores as geometric means for all matrixes. Then, we got final rankings of 15 standards along with their weights separately. 
Final Weights of 15 Standards On The Basis Of AHP Technique

\begin{tabular}{|c|c|c|c|c|c|}
\hline Standards & $\begin{array}{l}\text { Factor } \\
\text { Weight }\end{array}$ & Criteria & $\begin{array}{c}\text { Standard weight } \\
\text { in subset }\end{array}$ & $\begin{array}{c}\text { Final } \\
\text { weight }\end{array}$ & Ranking \\
\hline \multirow{5}{*}{$\begin{array}{l}\text { Management } \\
\text { factors }\end{array}$} & \multirow{5}{*}{0.368} & Short-long term planning & 0.324 & 0.092 & 2 \\
\hline & & Management information system & 0.250 & 0.098 & 1 \\
\hline & & Budgeting & 0.200 & 0.078 & 6 \\
\hline & & Research\&Development & 0.201 & 0.079 & 5 \\
\hline & & Role of manager public relations & 0.115 & 0.045 & 13 \\
\hline \multirow{3}{*}{ Cultural factors } & \multirow{3}{*}{0.446} & Making grounds for creativity flouridhing & 0.392 & 0.088 & 3 \\
\hline & & Positive attitude towards work & 0.308 & 0.069 & 7 \\
\hline & & Making participation public & 0.299 & 0.067 & 8 \\
\hline \multirow{3}{*}{$\begin{array}{l}\text { Social } \\
\text { factor }\end{array}$} & \multirow{3}{*}{0.310} & Job security & 0.401 & 0.061 & 10 \\
\hline & & Feeling of discrimination in workplace & 0.358 & 0.055 & 11 \\
\hline & & Working moral & 0.241 & 0.037 & 14 \\
\hline \multirow{2}{*}{$\begin{array}{c}\text { Psychophysic } \\
\text { factors }\end{array}$} & \multirow{2}{*}{0.244} & Job satisfaction & 0.581 & 0.048 & 12 \\
\hline & & Workplace safety & 0.419 & 0.035 & 15 \\
\hline \multirow{2}{*}{$\begin{array}{l}\text { Customer } \\
\text { factors }\end{array}$} & \multirow{2}{*}{0.304} & Customer satisfaction with organization internal part & 0.548 & 0.067 & 9 \\
\hline & & Time of delivering electricity services to customers & 0.452 & 0.081 & 4 \\
\hline
\end{tabular}

\section{2. $\quad$ Ranking Based On Fuzzy TOPSIS And Fuzzy AHP Techniques}

After data from response to the second questionnaire was entered into Expert Choice software, this software gave us separately the weights of standards obtained by experts views, with which we solve decision matrix by TOPSIS method. In this regard, the result from evaluation of each respondent was considered as a column of decision matrix.

Given that 25 questionnaires were completed and collected, we have a decision matrix with 15 rows (number of standards) and 25 columns (number of respondents) which is the basis of the work of other multiindex decision making techniques in this research. Following results were obtained after performing said techniques:

\begin{tabular}{|c|c|c|c|c|}
\hline Standards & Criteria & AHP & FAHP & FTOPSIS \\
\hline \multirow{5}{*}{ Management factors } & Short-long term planning & 2 & 4 & 4 \\
\hline & Management information system & 1 & 1 & 3 \\
\hline & Budgeting & 6 & 6 & 10 \\
\hline & Research\&Development & 5 & 5 & 11 \\
\hline & Role of manager public relations & 13 & 13 & 13 \\
\hline \multirow{3}{*}{ Cultural factors } & Making grounds for creativity flouridhing & 3 & 3 & 1 \\
\hline & Positive attitude towards work & 7 & 8 & 12 \\
\hline & Making participation public & 8 & 10 & 15 \\
\hline \multirow{3}{*}{$\begin{array}{l}\text { Social } \\
\text { factor }\end{array}$} & Job security & 10 & 7 & 7 \\
\hline & Feeling of discrimination in workplace & 11 & 11 & 5 \\
\hline & Working moral & 14 & 14 & 8 \\
\hline \multirow{2}{*}{ Psychophysic factors } & Job satisfaction & 12 & 9 & 2 \\
\hline & Workplace safety & 15 & 15 & 14 \\
\hline \multirow{2}{*}{ Customer factors } & Customer satisfaction with organization internal part & 9 & 12 & 6 \\
\hline & Time of delivering electricity services to customers & 4 & 2 & 9 \\
\hline
\end{tabular}


Based on ranks comparison table, it can be said that rankings from MCDM methods are different from each other. To specify optimal ranks and model, a ststistical analysis must be performed on models and standards in order to test the difference between results and to select optimal model and standards gained the same ranks, it should be noted that their rank arithmetic mean was used as the rank of all those standards.

\subsection{Testing supposition}

Due to different techniques mentioned in earlier chapters, it is possible to get different rankings for a single problem. In this case, combined POSET methods including Rank Means, Borda, and Kaplanmethods, are used to reach consensus on various rankings.

According to combined method, we have:

\begin{tabular}{|c|c|c|c|c|c|}
\hline Standards & Criteria & AHP & FAHP & FTOPSIS & Combined Rank \\
\hline \multirow{5}{*}{ Management factors } & Short-long term planning & 2 & 4 & 4 & 3.33 \\
\hline & Management information system & 1 & 1 & 3 & 1.66 \\
\hline & Budgeting & 6 & 6 & 10 & 7.33 \\
\hline & Research\&Development & 5 & 5 & 11 & 7 \\
\hline & Role of manager public relations & 13 & 13 & 13 & 13 \\
\hline \multirow{3}{*}{ Cultural factors } & Making grounds for creativity flouridhing & 3 & 3 & 1 & 2.33 \\
\hline & Positive attitude towards work & 7 & 8 & 12 & 9 \\
\hline & Making participation public & 8 & 10 & 15 & 11 \\
\hline \multirow{3}{*}{$\begin{array}{l}\text { Social } \\
\text { factor }\end{array}$} & Job security & 10 & 7 & 7 & 8 \\
\hline & Feeling of discrimination in workplace & 11 & 11 & 5 & 9 \\
\hline & Working moral & 14 & 14 & 8 & 12 \\
\hline \multirow{2}{*}{ Psychophysic factors } & Job satisfaction & 12 & 9 & 2 & 7.66 \\
\hline & Workplace safety & 15 & 15 & 14 & 14.66 \\
\hline \multirow{2}{*}{ Customer factors } & Customer satisfaction with organization internal part & 9 & 12 & 6 & 9 \\
\hline & Time of delivering electricity services to customers & 4 & 2 & 9 & 5 \\
\hline
\end{tabular}

As mentioned earlier, we used statistical test, Friedman's test, and spearman's Correlation coefficient to study the results difference. This study was done by SPSS software as follows:

a) Friedman's test for difference between 2 FUZZY AHP and FUZZY TOPSIS:

\begin{tabular}{|c|c|}
\hline \multicolumn{2}{|c|}{ Friedman's Test } \\
\hline Models & Rank mean \\
\hline FAHP & 1.5 \\
\hline FTOPSIS & 1.5 \\
\hline
\end{tabular}

b) Friedman's test for difference between 3 FAHP, AHP, FTOPSIS:

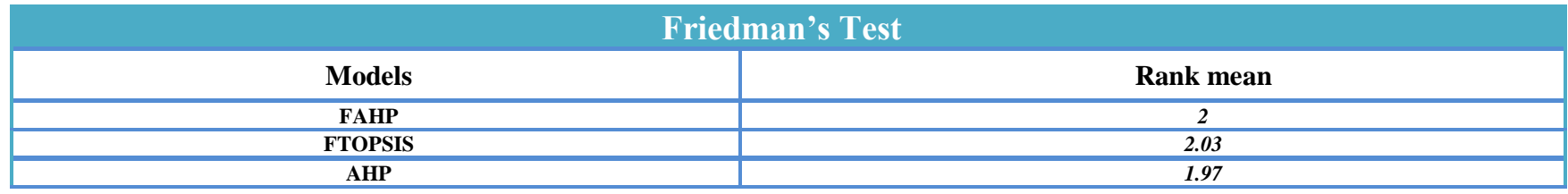


c) Spearman's correlation coefficient test between 2 AHP and FAHP models:

\begin{tabular}{|c|c|c|c|c|}
\hline & & & AHP & FAHP \\
\hline \multirow{6}{*}{ Spearman's Rho } & \multirow{3}{*}{ AHP } & Correlation coefficient & 1.000 & 0.919 \\
\hline & & Sig & - & 000 \\
\hline & & $\mathrm{N}$ & 15 & 15 \\
\hline & \multirow{3}{*}{ FAHP } & Correlation coefficient & 0.919 & 1.000 \\
\hline & & Sig & 000 & - \\
\hline & & $\mathrm{N}$ & 15 & 15 \\
\hline
\end{tabular}

d) Spearman's correlation coefficient test between 2 AHP and FTOPSIS models:

\begin{tabular}{|c|c|c|c|c|}
\hline & & & AHP & FTOPSIS \\
\hline \multirow{6}{*}{ Spearman's Rho } & \multirow{3}{*}{ AHP } & Correlation coefficient & $\overline{1.000}$ & 0.368 \\
\hline & & Sig & (--" & 0.177 \\
\hline & & $N$ & 15 & 15 \\
\hline & \multirow{3}{*}{ FTOPSIS } & Correlation coefficient & 0.368 & 1.000 \\
\hline & & Sig & 0.177 & - \\
\hline & & $\mathrm{N}$ & 15 & 15 \\
\hline
\end{tabular}

e) Spearman's correlation coefficient test between 2 FAHP and FTOPSIS models:

\begin{tabular}{|c|c|c|c|c|}
\hline & & & FAHP & FTOPSIS \\
\hline \multirow{6}{*}{ Spearman's Rho } & \multirow{3}{*}{ FAHP } & Correlation coefficient & 1.000 & 0.450 \\
\hline & & Sig & - & 0.092 \\
\hline & & $\mathrm{N}$ & 15 & 15 \\
\hline & \multirow{3}{*}{ FTOPSIS } & Correlation coefficient & 0.450 & 1.000 \\
\hline & & Sig & 0.092 & - \\
\hline & & $\mathrm{N}$ & 15 & 15 \\
\hline
\end{tabular}

\section{Analysis and Conclusion}

The results of calculated statistical tests:

A: on the basis of performed test, there is no difference between 2 FAHP and FTOPSIS models. Both give the same ranks to us.

B: on the basis of performed test, in FTOPSIS, FAHP, AHP models, either Certain or Fuzzy, all have the same ranks with slightly different results.

C: considering calculated correlations for 2 AHP and FAHP models, it can be concluded that both models have positive correlation, being close to one. Also, Sig is zero.

D: according to calculated correlations for 2 AHP and FTOPSIS models, we conclude that both models have positive correlation. But value of resultant Sig (0.177) shows that the results of ranking 2 models are not significant.

E: with respect to calculated correlations for 2 FAHP and FTOPSIS models, we concluded that both models have positive correlation. But value of resultant Sig (0.092) shows that the results of ranking 2 models are not significant.

\section{Suggestions}

Given the results of this study on decisions making to prioritize productivity objectives of Iranian Central Iron Ore company, it is suggested that combined ranking method, taking rank means, be empossible to choose optimal ranking method from fuzzy and non fuzzy methods. Using the results from combined method, we can 
rank factors based on their order of importance. The results from prioritizing factors include : The most and least important factors are management factors and workplace psychophysics factors, respectively .

Various results can be obtained with a brief look at ranking tables and classification of factors affecting productivity for different techniques. The results of this research confirm that in order to increase its productivity for each of standards having higher importance coefficient within optimal model , Iranian Central Iron Ore company must take serious steps on investing and planning .

In statistics, although correlation test is used as an alternative to similarity tests, the results of present research show we need assistance from statisticians to achieve more precise analogicometric tests. It appears that application of Friedman's test and spearman's correlation coefficient test was effective in testing hypotheses of this research . For future studies in this field, therefore, it is suggested first that future researchers embark on using other test methods(presently not known to researcher) ; or a specific test method be designed and presented to do studies similar to this research in statistics . Present study was limited to Iranian Central Iron Ore company , so it is recommended that future researchers follow it on other organizations and compare their results with ours to reach more reasonable results in the field of choosing optimal method and / or obtaining significant difference between Fuzzy and non-Fuzzy methods .

\section{References}

1- Azar, A., Rajabzadeh, A., (2003); Applied Decision Making By MADM Approach, Negah-e Danesh Press, pp1-200.

2- Al Saaty, Thomas., (2000); Decision Building For Managers Industrial Management Organization Press, Translated By Alisghar, T., No 1, PP1-65.

3- Amini-faskhoudi, A., (2008); "Evaluating Decision Making Units By Using Planning Model For Evaluating Group Fuzzy Prioritization", Humanism Research Magazine, Vol20, No1, PP9-15.

4- Sorayya'ee, S., (2007); "Prioritizing Indexes Of Evaluating Human Force Performance By Using Fuzzy AHP" International Management Conference, p2-14.

5- Ra'ee, R.,(2004); "Designing Multivariate ModelF For Investment Frojects", Tehran University In Iran Humanism Magazine, No1, PP2.

6- Taheri, Sh.,(2004); Productivity And It's Organizational Analysis, Nashr-e Havaye Tazeh Press, PP28-247.

7- Tavari, M., Et Al.,(2008);"Identidying And Prioritizing Factors Affecting Human Force Productivity By Using MADM Methods: A Aase Study On A Clothing Manufacturing Company In Yazs -Iran",Industrial Management Publication, No1, PP1-7.

8- Mo'meni, M.,(2007); New Topics In Operations Research, Tehran University Press- Iran, PP1-32.

9- Nouri, I., Et Al.,(2008); "Evaluating Education Quality By Fuzzy MCDM Technique, Knowledge Management Quarterly, No78, PP8.

10- Dagdeviren,M.,Yavuz,S.,Kilinc,N.,(2008). "Weapon Selection Using the AHP and TOPSIS Method under Fuzzy Environment", expert System with Applications, vol 21, pp1-9.

11- Dong,Y.,Shuiya,y.,(2009). "Linguistic Multi Decision Making Based On The USE Of Multiple Preference Relations", Fuzzy Sets and Systems, Vol160, pp8-12.

12- Kahraman,C.,Cebeci,U.,(2004). "Multi Attribute Comparison Of Catering Service Companies Using Fuzzy AHP The Case Of Turkey", Production Economices,pp2-4.

13- Wang,T.,Lee,H.,(2009). "Developing A Fuzzy TOPSIS Approach Based On Subjective Weights And Objective Weights", expert System with Applications, Vol 36, pp1-15. 